\title{
Avaliação do processo foto-Fenton na descoloração de um corante têxtil comercial
}

\section{Evaluation of the photo-Fenton process on discoloration of a commercial textile dye}

\author{
Andressa Antunes Bortoti ${ }^{1}$, Mauricio Ferreira da Rosa ${ }^{* 2}$, Reinaldo Aparecido Bariccatti ${ }^{3}$, \\ Viviane da Silva Lobo ${ }^{4}$
}

\begin{abstract}
Resumo
O presente trabalho teve por objetivo avaliar a aplicabilidade do processo foto-Fenton na degradação de um corante comercial (Guarany® Tingecor 09) de coloração vermelha. A otimização do processo foi realizada empregando-se um planejamento experimental $2^{3}$, variando-se os volumes de $\mathrm{Fe}^{3+} \mathrm{e}$ $\mathrm{H}_{2} \mathrm{O}_{2}$ adicionados e variando-se o $\mathrm{pH}$ do meio. As soluções contendo o corante e o reagente Fenton foram irradiadas em um fotorreator equipado com uma lâmpada de vapor de mercúrio $125 \mathrm{~W}$ e o desenvolvimento do processo foi acompanhado pela aquisição em intervalos de 10 minutos dos espectros de absorção UV-Vis. O planejamento experimental mostrou que os melhores resultados foram obtidos com menor volume de $\mathrm{Fe}^{3+}(0,1 \mathrm{~mL})$, maior volume de $\mathrm{H}_{2} \mathrm{O}_{2}(1,0 \mathrm{~mL})$ e $\mathrm{pH}$ 5. Após a degradação total do corante, aplicou-se o teste de fitotoxicidade, utilizando-se sementes de Lactuca sativa L.. Os resultados obtidos para a descoloração do corante foram satisfatórios e o teste de fitotoxicidade mostrou que os produtos gerados ao final do processo não apresentavam fitotoxicidade.
\end{abstract}

Palavras-chave: Corante. Fotodegradação. Processos Oxidativos Avançados. Química Ambiental

\begin{abstract}
The present study aimed to evaluate the applicability of photo-Fenton process for the degradation of a red colored commercial dye (Guarany ${ }^{\circledR}$ Tingecor 09 ). The process optimization was performed using a $2^{3}$ factorial design, varying the volumes added of $\mathrm{Fe}^{3+}$ and $\mathrm{H}_{2} \mathrm{O}_{2}$ and the $\mathrm{pH}$ of the medium. The solutions containing the dye and the Fenton reagent were irradiated in a photoreactor equipped with a mercury vapor lamp of $125 \mathrm{~W}$ and the process development was accompanied by the acquisition of the absorption spectra UV-Vis in 10-minute intervals. The experimental design has shown that the best results were obtained with less amount of $\mathrm{Fe}^{3+}(0.1 \mathrm{ml})$, larger volume of $\mathrm{H}_{2} \mathrm{O}_{2}(1.0 \mathrm{~mL})$ and $\mathrm{pH}$ 5. The efficiency of the dye decolorization was evaluated by a phytotoxicity test employing Lactuca sativa $\mathrm{L}$. seeds. The results showed to be satisfactory for the dye decolorization, and the wastes produced in the degradation process didn't show toxicity.
\end{abstract}

Keywords: Advanced Oxidative Processes. Dye. Environmental Chemistry. Photodegradation.

\footnotetext{
1 Aluna de Graduação em Química (Bacharelado), Centro de Engenharias e Ciências Exatas, UNIOESTE/Toledo. andressabortoti@hotmail.com

2 Professor Associado C da UNIOESTE, Docente do Programa de Mestrado em Ciências Ambientais, Centro de Engenharias e Ciências Exatas, UNIOESTE/Toledo.mauricio_rosa@ymail.com

3 Professor Associado C da UNIOESTE, Docente do Programa de Mestrado em Ciências Ambientais, Centro de Engenharias e Ciências Exatas, UNIOESTE/Toledo. bariccatti@yahoo.com.br

4 Professora Adjunta em Tecnologia em Processos Químicos, Docente do Programa de Mestrado em Processos Químicos e Biotecnológicos, UTFPR, campus Toledo. loboviviane@gmail.com
} 


\section{Introdução}

O setor têxtil desempenha um importante papel na economia brasileira. Segundo dados da Associação Brasileira da Indústria Têxtil e de Confecção (ABIT, 2010), o setor têxtil e de confecção nacional compreende mais de 30 mil empresas e gera 1,65 milhões de empregos em toda a sua extensa cadeia, que inclui fios, fibras, tecelagens e confecções. O país está na lista dos 10 principais mercados mundiais da indústria têxtil, bem como entre os maiores parques fabris do planeta; é o segundo principal fornecedor de índigo e o terceiro de malha, e está entre os cinco principais países produtores de confecção e é hoje um dos oito grandes mercados de fios, filamentos e tecidos.

Esta é uma atividade considerada de alto impacto ao meio ambiente, principalmente devido à produção de grandes volumes de rejeitos contendo altas cargas de compostos orgânicos e efluentes fortemente coloridos. Segundo Kunz et al. (2002) a poluição de corpos d'água com estes compostos provocam, além da poluição visual, alterações em ciclos biológicos afetando principalmente processos de fotossíntese. Peralta-Zamora e Souza (2005) apontam ainda que, além de alterar a atividade fotossintética, pela diminuição da transparência da água e a penetração da radiação solar, os efluentes provenientes do processo de tingimento podem modificar o regime de solubilidade dos gases, alterando assim a oxigenação da água.

Os corantes podem sofrer reações no meio ambiente, no qual interagem com as proteínas e enzimas presentes nos seres vivos, e acabam gerando compostos tóxicos tais como a toluidina e benzidina. Esses compostos são capazes de interagir com os grupos nucleofílicos do DNA, ocasionando mutações induzidas (GUARATINI; ZANONI, 2000).

Os maiores impactantes ao meio ambiente são os corantes classificados como azóicos e os reativos que normalmente são recalcitrantes, ou então apresentam uma cinética de degradação muito lenta para os processos biológicos convencionais, resultando em efluentes finais com uma coloração ainda intensa, sem contar ao fato de serem espécies químicas de reconhecido efeito carcinogênico e mutagênico (KUNZ, 1999).

Apesar de existirem legislações e políticas de preservação ambiental, poucas indústrias, principalmente as pequenas e micro indústrias, não realizam o tratamento de seus efluentes, ou então, se possuem tratamento, este é pouco eficaz, principalmente porque estes contaminantes são resistentes à degradação via tratamento físicoquímico ou então são biorefratários, dificultando assim um tratamento biológico. Por esses fatores, surge uma importante busca pela melhoria de processos de tratamento desses materiais, a fim de reaproveitar a água nos processos têxteis, diminuindo assim o impacto ambiental que essas empresas ocasionam.

Uma alternativa para reduzir os subprodutos e a cor desses efluentes são os processos oxidativos avançados (POA). Esses processos se baseiam na produção de radicais hidroxilas $(\mathrm{HO} \cdot)$, que são espécies altamente reativas que podem iniciar diferentes tipos de reações com diferentes grupos funcionais formando radicais orgânicos instáveis que podem ser posteriormente oxidados em dióxido de carbono, água e sais inorgânicos inócuos, processo conhecido como mineralização (NOGUEIRA; OLIVEIRA; SILVA, 2004).

Neste tipo de tratamento se incluem as técnicas de fotólise homogênea e heterogênea, os processos utilizando dióxido de titânio, ozônio, peróxido de hidrogênio e a combinação de peróxido de hidrogênio e solução de ferro, conhecida como Fenton. Essas técnicas geralmente são utilizadas em consórcio com a aplicação de luz UV, que potencializam sua eficácia, sendo denominadas técnicas fotocatalíticas.

O processo foto-Fenton tem se mostrado eficaz na degradação de contaminantes orgânicos e corantes. O sucesso do processo se deve ao fato do peróxido 
de hidrogênio reagir com luz UV e gerar radical hidroxila, que atua como um poderoso oxidante $(2,8$ eV) (SWAMINATHAN; MURUGANANDHAM, 2004). Este radical é não seletivo e promove a degradação de compostos orgânicos em tempos relativamente pequenos, reagindo muito mais rápido que outros oxidantes como o ozônio.

Esta característica faz com que o processo foto-Fenton apresente um grande potencial para a degradação de inúmeras espécies de relevância ambiental promovendo mineralizações em tempos bem menores, quando comparado aos demais POA. Este processo consiste no emprego de íons Fe (II) e peróxido de hidrogênio (reação Fenton) associado à radiação na região do ultravioleta (UV), havendo uma ação sinergética entre ambos. No processo Fenton o íon $\mathrm{Fe}$ (II) reage com $\mathrm{H}_{2} \mathrm{O}_{2}$ gerando o íon Fe (III) e radical hidroxila (HO·) (Equação 1). Posteriormente o íon Fe (III) novamente reduzido ao íon Fe (II) gera o radical peroxila (HOO·) (Equação 2).

$$
\begin{aligned}
& \mathrm{Fe}^{2+}+\mathrm{H}_{2} \mathrm{O}_{2} \rightarrow \mathrm{Fe}^{3+}+\mathrm{OH} \cdot+\mathrm{OH}^{-} \\
& \mathrm{Fe}^{3+}+\mathrm{H}_{2} \mathrm{O}_{2} \rightarrow \mathrm{Fe}^{2+}+\mathrm{OOH} \cdot+\mathrm{H}^{+}
\end{aligned}
$$

$\mathrm{Na}$ presença de luz esta reação pode ser amplamente aumentada, pois além do processo Fenton já mencionado, ocorre também a fotorredução de Fe (III) a Fe (II) (Equação 3) (HE; LEI, 2004).

$$
\mathrm{Fe}(\mathrm{OH})^{2+}+h v \rightarrow \mathrm{Fe}^{2+}+\mathrm{HO}
$$

o qual reage posteriormente com $\mathrm{H}_{2} \mathrm{O}_{2}$. Como a reação ocorre na forma de um ciclo, isto é, podese iniciar a reação tanto com Fe (II) como Fe (III), e assim, pode-se associar ao aumento da decomposição, a absorção da luz UV e à fotólise de complexos orgânicos de Fe (III) gerados durante a decomposição como mostrado no esquema abaixo (Esquema 4):

$$
\mathrm{Fe}^{3+}+\mathrm{H}_{2} \mathrm{O}_{2}+\mathrm{luz} \rightarrow \mathrm{Fe}^{2+}+\mathrm{HO} \cdot+\mathrm{HO}-
$$

A grande vantagem deste método quando comparado a outros métodos de tratamentos de resíduos é, além da sua grande eficácia, o baixo custo e a pronta disponibilidade comercial dos reagentes envolvidos.

A eficiência de um processo de degradação pode ser avaliada por ensaios ecotoxicológicos. Vários são os bioindicadores que podem ser empregados para este fim, tais como os micro-crustáceos Artemia salina e Daphnia magna. Ensaios de fitotoxicidade também são muito empregados com esta finalidade avaliativa de processos de degradação. Um dos ensaios mais utilizados empregam sementes de Lactuca sativa L., devido a sua suscetibilidade a agentes contaminantes (MESSIAS et al., 2009).

Neste ensaio o que se verifica é a influência de substâncias presentes no meio no crescimento e desenvolvimento de plantas (CHANG; GRANTO; PAGE, 1992). Desta maneira qualquer alteração nas condições ambientais pode ser detectada pelas plantas, afetando sua produção, acumulação e ativação de compostos na forma de enzimas ou metabólitos em resposta ao estresse ocasionado, assim como pela redução na produção de matéria seca e no crescimento radicular (HAUSCHILD, 1993).

Este trabalho tem como objetivo estudar a aplicabilidade do processo foto-Fenton na descolorização de um corante têxtil comercial determinando-se as melhores condições reacionais pelo emprego de planejamento experimental e verificar, por meio do bioensaio de fitotoxicidade com Lactuca sativa L. (alface), a toxicidade do resíduo gerado por este processo de fotodegradação.

\section{Materiais e Métodos}

O corante têxtil comercial de coloração vermelha, Guarany Tingecor 09 utilizado neste estudo foi adquirido no comercio local. Esse corante é utilizado no tingimento de roupas em ambiente doméstico e pode ser facilmente obtido no comércio. 
O rótulo do produto não apresentava as substâncias que compunham a formulação, informando apenas que se tratava de corantes das classes dipersivo, reativo e de enxofre, não sendo possível, portanto, se preparar soluções de corante com concentrações definidas em mol $\mathrm{L}^{-1}$. Assim decidiu-se padronizar as soluções por sua absorbância máxima $\left(\lambda_{\max }\right)$, que ocorreu no comprimento de onda de $495 \mathrm{~nm}$, ajustando-se esta em torno de 1,0 (um).

Inicialmente foi preparada uma solução solubilizando-se $0,508 \mathrm{~g}$ do corante em $250 \mathrm{~mL}$ de água destilada $\left(2,032 \mathrm{~g} \mathrm{~L}^{-1}\right)$. Desta solução retirouse uma alíquota de $4 \mathrm{~mL}$, a qual foi avolumada a $25 \mathrm{~mL}$ com água destilada. A concentração desta solução de análise era de $0,3251 \mathrm{~g} \mathrm{~L}^{-1}$.

Para este trabalho utilizou-se um planejamento de $2^{3}$, obtendo-se oito experimentos distintos, realizados em triplicata. Para a realização destes experimentos foram testadas soluções de $\mathrm{Fe}^{3+}(1,8$ x $\left.10^{-4} \mathrm{~mol} \mathrm{~L}^{-1}\right), \mathrm{H}_{2} \mathrm{O}_{2}(30 \% \mathrm{v} / \mathrm{v})$ e $\mathrm{pH}$, empregandose níveis alto $(+)$ e baixo (-), baseado no volume dos reagentes adicionados ou do $\mathrm{pH}$ empregado, conforme a Tabela 1 .

Tabela 1 - Condições pré-estabelecidas dos volumes de $\mathrm{Fe}^{3+}(\mathrm{Fe}), \mathrm{H}_{2} \mathrm{O}_{2}(\mathrm{H})$ e $\mathrm{pH}$, para o estudo do planejamento experimental.

\begin{tabular}{ccc}
\hline Variável & Nível Baixo (-) & Nível alto $(+)$ \\
\hline Fe $(\mathrm{mL})$ & 0,1 & 0,6 \\
$\mathrm{H}(\mathrm{mL})$ & 0,5 & 1,0 \\
$\mathrm{pH}$ & 3,0 & 5,0 \\
\hline
\end{tabular}

Para a irradiação foi utilizado um béquer de 100 $\mathrm{mL}$ no qual foram colocados $25 \mathrm{~mL}$ da amostra do corante e acrescidos dos respectivos volumes das soluções de $\mathrm{Fe}^{3+}$ e $\mathrm{H}_{2} \mathrm{O}_{2}$. Para as amostras as quais o $\mathrm{pH}$ foi ajustado em 3 foi empregado acido acético $2 \mathrm{~mol} \mathrm{~L}^{-1}$.

Na Figura 1 abaixo é apresentado um esquema do fotorreator construído para a irradiação da amostra. Este consistia de uma caixa de madeira (C) com medidas aproximadas de $80 \times 50 \times 50$ cm (A x L x P). Para a irradiação foi empregada uma lâmpada de vapor de mercúrio 125 W (GE), cujo bulbo externo retirado para evitar o efeito de filtro da radiação UV, posicionada no topo da caixa (A). No interior desta foi colocada uma placa de agitação (D), que mantinha a solução a ser irradiada (B) continuamente agitada. Para regular a distância entre a fonte de irradiação e a amostra a ser irradiada, o agitador magnético foi colocado sobre um lab-jack (macaco) que era erguido ou abaixado de acordo com a necessidade, mantendo o béquer o mais próximo possível da lâmpada.

Figura 1 - Esquema do fotorreator utilizado.

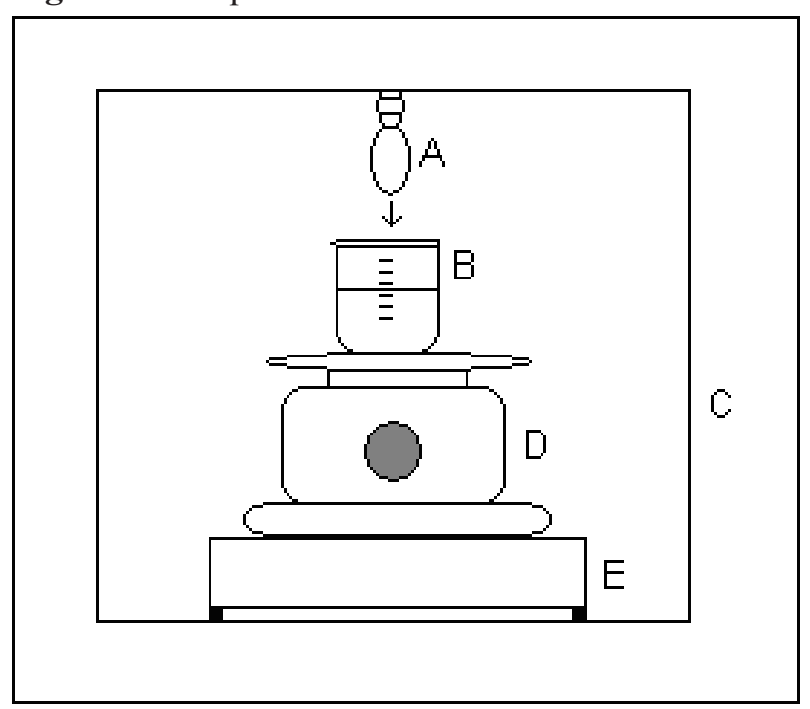

Fonte: o próprio autor.

A evolução do processo fotodegradativo foi acompanhada pela obtenção dos espectros de absorção em intervalos de tempo de 10 minutos. Assim, uma alíquota era retirada e transferida para uma cubeta de quartzo de caminho óptico de $1 \mathrm{~cm}$ e analisado no espectrofotômetro Shimadzu 1601-PC.

A avaliação cinética do processo fotodegradativo foi verificado considerandose uma cinética de primeira ordem traçando- 
se um gráfico de $\ln \left(\mathrm{A}_{0} / \mathrm{A}\right)$ vs tempo para todos experimentos, tendo como referência a absorbância da banda no comprimento de onda de $495 \mathrm{~nm}$ até o tempo limite de 40 minutos de irradiação

Para o teste de fitotoxicidade, utilizou-se a solução totalmente descolorida no processo foto-Fenton de acordo com as condições préestabelecidas para a realização do planejamento experimental. As soluções sofreram duas diluições com adição de água destilada, obtendo as seguintes características para o teste: $100 \%$ da solução, $50 \%$ e $25 \%$ v/v. A amostra controle foi saturada apenas com água destilada.

De acordo com o protocolo do ensaio, um disco de papel de filtro foi colocado em uma placa de Petri (40 mm de diâmetro) previamente marcada com a diluição correspondente, assim como a data de início e do término do bioensaio. O papel foi posteriormente saturado com 1,6 mL da respectiva solução de diluição, cuidando-se para que não houvesse formação de bolhas de ar. Com a ajuda de uma pinça, oito sementes foram cuidadosamente acomodadas sobre o papel com espaço suficiente entre elas para permitir o crescimento das raízes. As placas foram cobertas para evitar a perda de umidade e na sequência incubadas ao abrigo de luz, durante 9 dias (120 h) a uma temperatura de $25^{\circ} \mathrm{C}$.

A avaliação dos efeitos foi realizada comparando-os com a amostra controle, cuja exposição ocorre apenas em presença de água destilada e sujeitos às mesmas condições de ensaio, exceto pela ausência da amostra. Terminado o período de exposição, quantifica-se o efeito na germinação e o crescimento atingido pelas partes aéreas.

\section{Resultados e Discussão}

A solução do corante demorou em média 60 minutos para atingir a total descoloração, dependo da concentração de $\mathrm{Fe}^{3+}, \mathrm{H}_{2} \mathrm{O}_{2}$ e o pH do meio em que estava. Desta maneira utilizou-se o valor da absorbância obtida no tempo igual a 40 minutos de irradiação para avaliar os efeitos dos tratamentos para o planejamento experimental. Porém para avaliar a aplicação do teste fitotóxico com Lactuca sativa L., utilizou-se o corante totalmente descolorido, de modo a poder avaliar o resíduo gerado pelo tratamento do foto-Fenton por completo.

A partir das condições de fotodegradação, apresentadas na Tabela 1, foram realizados testes através do planejamento experimental do tipo $2^{3}$ (Tabela 2) para obter a melhor condição de fotodegradação e conhecer o comportamento dos corantes para posterior aplicação em efluentes reais. Os contrastes dos níveis estão representados em + e -, para os níveis alto e baixo respectivamente, e os resultados obtidos pela porcentagem de absorção em relação à absorbância inicial e final, no comprimento de onda de $495 \mathrm{~nm}$, apresentam seus valores para as tréplicas (1, 2 e 3$)$, no qual foram realizados 8 experimentos.

Tabela 2 - Condições pré-estabelecidas para oito experimentos (tréplica) realizados através da combinação de níveis altos e baixos de $\mathrm{Fe}^{3+}, \mathrm{H}_{2} \mathrm{O}_{2}$ e pH.

\begin{tabular}{ccccccc}
\hline $\operatorname{Exp}$ & $\begin{array}{c}\mathbf{F e} \\
(\mathbf{m L})\end{array}$ & $\begin{array}{c}\mathbf{H} \\
(\mathbf{m L})\end{array}$ & $\mathbf{p H}$ & $\mathbf{1}$ & $\mathbf{2}$ & $\mathbf{3}$ \\
\hline $\mathbf{1}$ & + & - & - & 62,4045 & 55,4357 & 63,1708 \\
$\mathbf{2}$ & - & - & - & 89,1766 & 90,6672 & 87,1708 \\
$\mathbf{3}$ & + & + & - & 67,5058 & 66,3713 & 70,9422 \\
$\mathbf{4}$ & - & + & - & 91,0333 & 87,5947 & 91,7099 \\
$\mathbf{5}$ & + & - & + & 57,2223 & 54,9886 & 65,6789 \\
$\mathbf{6}$ & - & - & + & 90,7057 & 89,8093 & 93,2031 \\
$\mathbf{7}$ & + & + & + & 61,8274 & 61,9133 & 69,4078 \\
$\mathbf{8}$ & $\mathbf{-}$ & + & + & 98,3402 & 96,7118 & 97,4398 \\
\hline
\end{tabular}

A Tabela 3 apresenta a análise realizada pelo modelo experimental $2^{3}$ pelo programa ANOVA e seu respectivo modelo. 
Tabela 3 - Análise de variância (ANOVA) obtida pelo planejamento experimental $2^{3}$.

\begin{tabular}{cccc}
\hline Variável & Efeito $(\%)$ & p-valor & Significância \\
\hline $\mathrm{Fe}$ & $-29,0$ & 0,000 & Significante \\
$\mathrm{H}$ & 4,97 & 0,001 & Significante \\
$\mathrm{pH}$ & 1,16 & 0,390 & Insignificante \\
$\mathrm{Fe} \times \mathrm{H}$ & 1,42 & 0,296 & Insignificante \\
$\mathrm{Fe} \times \mathrm{pH}$ & $-3,52$ & 0,016 & Significante \\
$\mathrm{H} \mathrm{x} \mathrm{pH}$ & 0,69 & 0,605 & Insignificante \\
Fe x H x pH & $-2,01$ & 0,147 & Insignificante \\
\hline \hline
\end{tabular}

Significante quando o p-valor é menor que 0,05 , considerando $95 \%$ de confiabilidade.

Insignificante quando o p-valor for maior que 0,05 .

Para se obter uma otimização dos resultados, utilizou-se o planejamento experimental para predizer a melhor quantidade de ferro e peróxido visando um máximo de eficiência com menor consumo dos reagentes no decaimento das bandas de absorbância do corante. No entanto, vale conhecer a importância desses parâmetros encontrados na Tabela 3, visto que cada um deles apresenta uma contribuição significativa para a análise deste modelo. Sendo assim, um efeito só é considerado estatisticamente significativo com $95 \%$ de confiança, ou seja, o p-valor deverá ser inferior a $5 \%$.

De acordo com os dados contidos na Tabela 3, observa-se que o $\mathrm{H}_{2} \mathrm{O}_{2}$ apresenta significância positiva na reação, isto é quando utilizado um volume maior, a eficácia do processo durante a reação possui um aumento de cerca de $5 \%$. Por outro lado a interação entre as variáveis $\mathrm{Fe}^{3+}$ e $\mathrm{pH}$ apresentam significância negativa na reação, ou seja, quando utiliza-se um volume maior de Fe num valor de $\mathrm{pH}$ maior, observa-se que a eficiência do processo na reação diminui cerca de 3,5\%, conforme a Tabela 3 . Este efeito pode ser observado pela Figura 3, onde no nível maior de $\mathrm{pH}$, quando o Fe muda do maior nível para o menor, nota-se que ocorre o aumento no efeito, sendo este bem maior do que o observado no nível baixo de $\mathrm{pH}$.

Figura 2 - Gráfico da interação entre pH (nível baixo em azul e nível alto em vermelho) e $\mathrm{H}_{2} \mathrm{O}_{2}$.

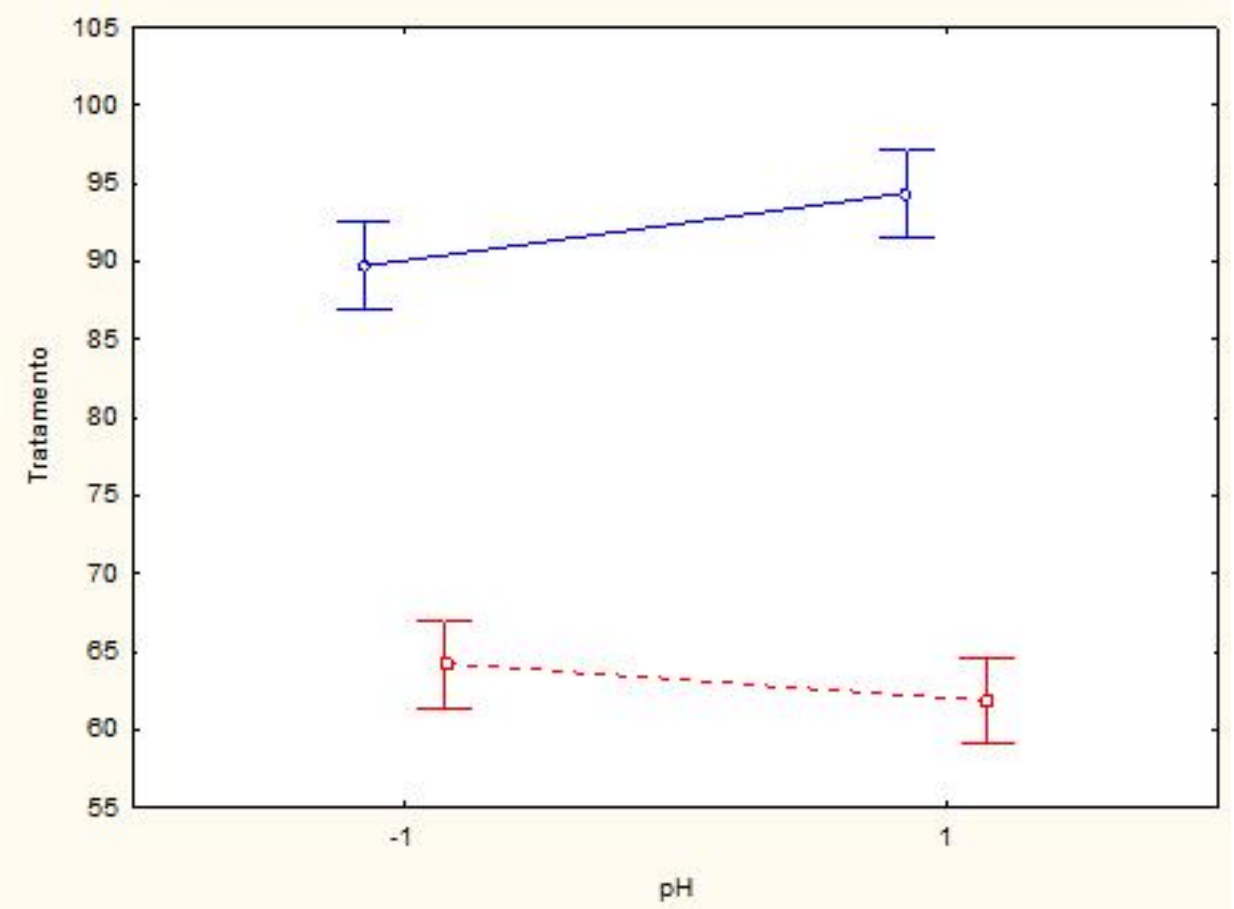

Fonte: o próprio autor. 
Baseado na análise da ANOVA verifica-se que $96,96 \%$ dos dados são explicados pelo modelo, no qual podem ser descritos com $95 \%$ de confiança de acordo com a equação (5).

$$
\begin{aligned}
& \left(1-\mathrm{T}_{\mathrm{R} 495 \mathrm{~nm}}\right)=77,52-14,50 * \mathrm{Fe}+2,48 * \mathrm{H}_{2} \mathrm{O}_{2}-1,761 \mathrm{Fe} * \\
& \mathrm{H}_{2} \mathrm{O}_{2}
\end{aligned}
$$

Desta maneira, a análise estatística pressupõe que a melhor condição de degradação, ocorre quando utilizado um menor volume de $\mathrm{Fe}^{3+}$, maior volume de $\mathrm{H}_{2} \mathrm{O}_{2}$ e pH mais elevado. Pela equação acima é possível observar essas condições. Ao observar essas condições na Tabela 2, verifica-se que a melhor condição é referente ao experimento 8 , cujas porcentagens de degradação ultrapassaram $96 \%$.

Quando é utilizada uma concentração alta de ferro, ocorre a formação do hidróxido de ferro, sendo observada precipitação, fato verificado no experimento 5. O que justifica a diminuição da cinética da reação de processo foto-Fenton, neste caso.

De acordo com Lima (2006), observa-se que o processo foto-Fenton pode ser utilizado em um pH mais elevado do que o considerado ótimo por outros autores, que no caso compreenderia a faixa de 3, porém nestas condições o autor salienta que há precipitação de íons férricos que envolvem a geração de óxidos férricos hidratados, cujo favorecimento se deve ao $\mathrm{pH}$ alto. Malato et al. (2009), referem-se a alguns casos em que o pH na faixa de 4 e 5 pode ser considerado ideal, pois consegue evitar a precipitação de íons férricos, embora seus experimentos tenham sido realizados com outro corante.

A Figura 3 apresenta o comportamento degradativo do corante quando exposto a irradiação durante 40 minutos. Podendo ser verificado que após o tempo de 20 minutos de irradiação o corante encontra-se em condições de total mineralização.

Figura 3 - Espectros de absorção do corante no experimento 8 em diferentes tempos de irradiação

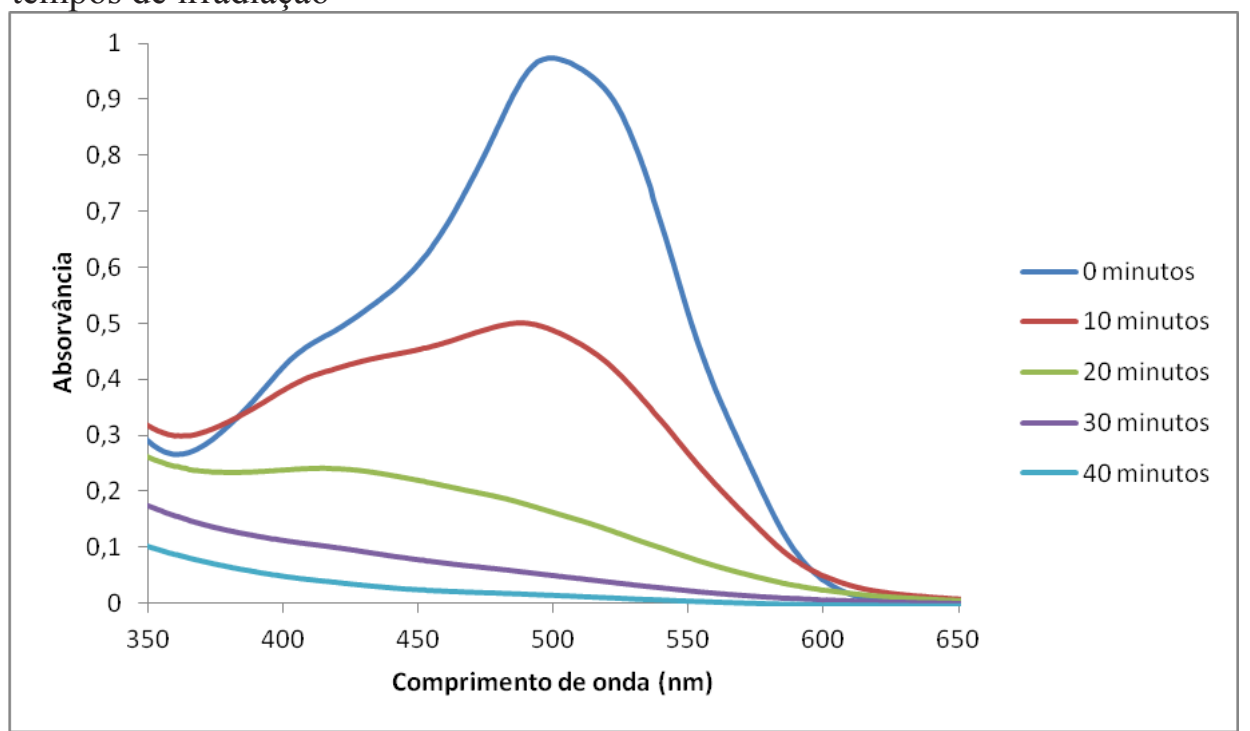

Fonte: o próprio autor.

Os parâmetros cinéticos foram esboçados na Tabela 4, e foram obtidos pelo gráfico apresentado na Figura 4, cujas constantes de velocidade $(k)$ foram obtidas pelos coeficientes angulares de cada reta para os respectivos experimentos. 
Figura 4 - Gráfico da $\ln \left(\mathrm{A} / \mathrm{A}_{0}\right)$ x tempo (minutos)

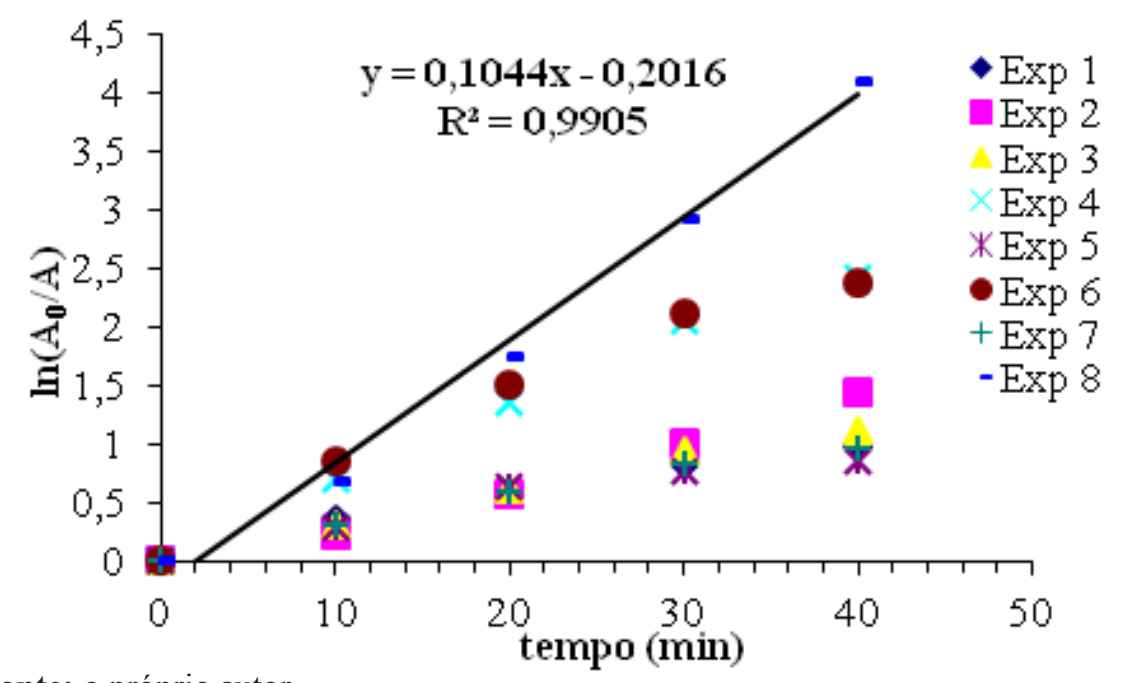

Fonte: o próprio autor.

Os parâmetros cinéticos, considerando-se uma reação de primeira ordem, foram obtidos por meio do gráfico do $\ln \left(\mathrm{A}_{0} / \mathrm{A}\right)$ vs tempo de irradiação, cujo coeficiente angular da reta fornece a constante de velocidade da reação $(\mathrm{k})$, sendo o tempo de meiavida calculado pela expressão $\mathrm{t}_{1 / 2}=\ln 2 / \mathrm{k}$.

A Tabela 4 comprova que o experimento 8 realmente foi mais eficiente, visto que sua constante de velocidade de reação obteve o valor de 0,1044 $\min ^{-1} \mathrm{e}$, consequentemente, o menor tempo de meiavida, igual a 6,64 minutos.

Tabela 4 - Parâmetros cinéticos para o decaimento das bandas do espectro.

\begin{tabular}{rccc}
\hline $\exp$ & $k\left(\mathrm{~min}^{-1)}\right.$ & $\mathrm{R}^{2}$ & $\mathrm{t}_{1 / 2}(\min )$ \\
\hline $\mathbf{1}$ & 0,0243 & 0,9812 & 28,52 \\
$\mathbf{2}$ & 0,0365 & 0,9858 & 18,99 \\
$\mathbf{3}$ & 0,0287 & 0,9928 & 24,15 \\
$\mathbf{4}$ & 0,0618 & 0,9895 & 11,23 \\
$\mathbf{5}$ & 0,0218 & 0,9320 & 31,79 \\
$\mathbf{6}$ & 0,0602 & 0,9689 & 11,51 \\
$\mathbf{7}$ & 0,0243 & 0,9812 & 28,52 \\
$\mathbf{8}$ & 0,1044 & 0,9905 & 6,64 \\
\hline \hline
\end{tabular}

Durante a execução do experimento, verificou-se que a temperatura no interior fotorreator aumentava em cerca de $10{ }^{\circ} \mathrm{C}$,o que acarretava no aumento da temperatura do meio reacional. Nestes casos foi observado que o tempo reacional aumentava. Isto acontece porque a elevação da temperatura atua cataliticamente na decomposição do peróxido reacional. Segundo Malato et al. (2009), o aumento da temperatura, acarreta o aumento do consumo de peróxido para a redução dos íons férricos, embora não haja a produção do radical hidroxila. Desta maneira, nota-se que o processo foto-Fenton não consegue degradar totalmente $\mathrm{o}$ corante. Entretanto este aumento da temperatura observado no experimento não foi suficiente para verificar a descontinuação da degradação ao longo do tempo.

$\mathrm{O}$ teste de fitoxicidade foi realizado com o resíduo gerado pela degradação no processo fotoFenton do experimento 8 .

A Tabela 5 apresenta os valores médios observados, em milímetros, para o crescimento da parte aérea da $L$. sativa quando se empregou este resíduo em diferentes proporções. A proporção de $100 \%$ corresponde ao cultivo das sementes utilizando o resíduo do corante degradado sem 
diluição. As proporções de $50 \%$ e 25\% correspondem as diluições, empregando-se água destilada, de 1:1 e 1:3, respectivamente. No controle positivo foi empregado somente água destilada.

Tabela 5 - Média do crescimento das partes aéreas da $L$. sativa L. medido em milímetros.

Comprimento da parte aérea $(\mathrm{mm})$

\begin{tabular}{cc} 
Controle & $36,6 \pm 0,1$ \\
$\mathbf{1 0 0 \%}$ & $24,2 \pm 0,1$ \\
$\mathbf{5 0 \%}$ & $28,9 \pm 0,1$ \\
$\mathbf{2 5 \%}$ & $33,5 \pm 0,1$ \\
\hline
\end{tabular}

Observa-se que, mesmo no cultivo utilizando apenas o resíduo como meio, a L. sativa apresentou crescimento favorável. Desta maneira verifica-se que o resíduo gerado pela degradação do corante não apresenta teores tóxicos ao crescimento de plantas, embora se verifique um pequeno retardo no crescimento da plântula conforme aumenta-se a concentração do resíduo.

\section{Conclusões}

A aplicação do processo foto-Fenton correspondeu bem às expectativas, uma vez que se mostrou eficaz para descoloração do corante. Dos experimentos realizados, segundo um planejamento experimental $2^{3}$, aquele que apresentou melhores resultados empregou a menor concentração de $\mathrm{Fe}(\mathrm{II})$, o maior volume de $\mathrm{H}_{2} \mathrm{O}_{2}$ e o maior $\mathrm{pH}$. O teste de fitotoxicidade utilizando Lactuca sativa $L$. mostrou que o efluente submetido à degradação apresentou baixa toxicidade, comparado com o controle.

\section{Referências}

ASSOCIAÇÃO BRASILEIRA DA INDÚSTRIA TÊXTIL E DE CONFECÇÃO - ABIT. Disponível em: $<$ http://www.abit.org.br/site/ texbrasil/default.asp?id_menu=2\&idioma $=$ PT\&r $\mathrm{nd}=201011717133312>$. Acesso em: 5 jan. 2010.
CHANG, A. C.; GRANTO, T. C.; PAGE, A. L. A methodology for establishing phytotoxicity criteria for chromium, copper, nickel and zinc in agricultural land application of municipal sewage sludges. Journal of Environmental Quality, Madison, v. 21, n. 4, p. 521536, 1992.

GUARATINI, C. C. I.; ZANONI, M. V. B. Corantes têxteis. Química Nova, São Paulo, v. 23, n. 1, p. 71-78, 2000.

HAUSCHILD, M. Z. Chromiun content of leaves reveals chromium (III): Stress of higher plants before sensitive biomarkers. Science of the Total Environment, Amsterdã, v. 134, supl. 2, p. 1345-1352, 1993.

HE, F.; LEI, L. Degration kinetics and mechanisms of phenol in photo-Fenton processos. Journal of Zhejiang University Science A, Zheijiang, v. 5, n. 2, p. 198-205. 2004.

KUNZ, A. Remediação de efluente têxtil: combinação entre processo químico (ozônio) e biológico ( $P$. Chrysosporium). 1999. Tese (Doutorado em Química) - Instituto de Química, Universidade Estadual de Campinas, Campinas.

KUNZ,A.;ZAMORA,P.P.; MORAES, S.G.;DURÁN, N. Novas tendências no tratamento de efluentes têxteis. Química Nova, São Paulo, v. 25, n. 1, p. 78-82, 2002.

LIMA, C. Degradação de corantes reativos $e$ remediação de efluentes têxteis por processos oxidativos avançados envolvendo ferro metálico. 2006. Dissertação (Mestrado em Química Analítica) Universidade Federal do Paraná, Curitiba.

MALATO, S.; FERNÁNDEZ-IBÁÑEZ, P.; MALDONADO, M. I.; BLANCO, J.; GERNJAK, W. Descontamination and disinfection of water by photocatalysic: recent overview and trens. Catalysis Today, Amsterdã, v. 69, p. 323-340, 2009.

MESSIAS, R. S.; PAGEL, I. A.; SILVEIRA, C. A. P.; PILLON, C. N. Uso da água de Xisto como matériaprima de fertilizantes foliares para cultura da alface. In: CONGRESSO BRASILEIRO DE ROCHAGEM, 2009, Brasília. Anais... Brasília, 2009.p. 249. Disponível em <http://www.scribd.com/doc/33330677/Anais-ICongresso-Brasileiro-de-Rochagem $>$ Acesso em: 8 out. 2010. 
NOGUEIRA, R.; OLIVEIRA, M.; SILVA, M. Estudo da aplicação do processo foto-fenton solar na degradação de efluentes de indústrias de tintas. Eclética Química, Araraquara, v. 29, n. 2, p. 19-26, 2004.

PERALTA-ZAMORA, P.; SOUZA, C. Degradação de corantes reativos pelo sistema ferro metálico/ peróxido de hidrogênio. Química Nova, São Paulo, v. 28, n. 2, p. 226-228, 2005.

SWAMINATHAN, M.; MURUGANANDHAM, M. Decolourisation of reactive orange 4 by fenton and photo-fenton oxidation technology. Dyes and Pigments, Amsterdã, v. 63, p. 315-321, 2004. 